\title{
Exploring New Fields for the Journal
}

\author{
Douglas McDougall ${ }^{1}$
}

Accepted: 8 July 2021 / Published online: 23 July 2021

(C) Ontario Institute for Studies in Education (OISE) 2021

We are now in our second year of the COVID-19 pandemic. Over the past 16 months, schools have been opened and closed numerous times, many universities remain closed, and educators at all levels have had to teach in ways that many had not experienced in the past. It is in this environment that we look forward to each issue of CJSMTE to better understand Science, Mathematics, Technology, and STEM education. I think that this issue will provide you with further insights into these fields. In Issue 20.4, we suggested that we would find opportunities to expand our reach around the world. In this issue, there are articles from Canada, the USA, France, the UK, Costa Rica, and the Netherlands.

It is my great pleasure to announce the addition of Dr. Isha DeCoito as an editor for Science (English Language) for the Canadian Journal for Science, Mathematics, and Technology Education. Dr. DeCoito is an Associate Professor in Curriculum Studies at Western University, where she developed and currently coordinates the STEM specialty focus in the teacher education program. Isha is a former CJSMTE Editorial Assistant and Managing Editor of the journal. She has also been a guest editor of special issues in the Journal.

In this issue, we have a special theme called Responding to Anti-Black Racism in Science, Mathematics, Technology, and STEM Education. Co-editors Fikile Nxumalo and Wanja Gitari (2021) assembled a highly knowledgeable group of authors to respond to this topic in a variety of settings: science, mathematics, engineering, computer science, STEM, and medicine. They have written a separate editorial to describe the manuscripts in their special theme.

Marchand and Munier (2021) explore the teaching of space as part of the science and mathematics curriculum in elementary schools in Québec and France. The article describes their investigation of an Activity-Generating Structure to develop and analyze teaching sequences. They found that, by adapting a traditional way to teach about the discovery of the compass, they can promote students' acquisition of spatial understanding. They pose a general question about the place and role of manipulation in the science and mathematics class.

Douglas McDougall

doug.mcdougall@utoronto.ca

1 Ontario Institute for Studies in Education, University of Toronto, 252 Bloor Street West, Toronto, ON M5S 1V6, Canada 
The COVID-19 pandemic has changed some of our approaches to teaching and learning. Braund (2021) proposes that we need a "critical STEM literacy" to engage with STEM knowledge so that we can make better personal health decisions. He draws on experience of COVID-19 in the UK and how mathematical modeling can help us better understand the case data. This article will help us to reinforce the importance of careful empirical validation of new knowledge and how social scientific issues should form the foundation of STEM integration.

Ramírez Montes et al. (2021) focus their research on mathematical modeling, particularly involving the concept of solving a system of linear equations. They investigated the modeling competencies of undergraduate students in Costa Rica in linear algebra concepts. They found that the students used a variety of routes to solve the linear equations, including linear and non-linear routes, and the use of technology to build models. They also found that the validation step was not normally done. The authors suggested that the students had a lack of experience working with tasks with real contexts. This reinforces the view that students need more practice to develop competency in validating results from real-life contexts.

Bronkhorst et al. (2021) analyzed video recordings of secondary school student discussions as they worked on logical reasoning tasks. These tasks were both closed tasks where all of the details are provided and everyday tasks with implicit premises. They found that students are able to make connections using letter symbols but need more practice with Venn and Euler diagrams. The article continues the discussion about visual representation and finding ways to support teaching and learning in logical reasoning.

George and Voutsina (2021) investigated strategies that students use for finding the fraction associated with solving partitive quotient problems. They showed that, initially, students used more than one strategy with the early tasks but eventually settled on one strategy. These findings are helpful to identify possible strategies that can be used to solve partitive quotient tasks. In addition, the paper illustrates the need to introduce different fraction sub-constructs early so that students do not believe that there is only one meaning of fractions.

Abboud and Rogalski (2021) investigated teacher's activity when they are working with digital technologies in the classroom. As those of us who have taught using technology, we know that we have unexpected interruptions and difficulties in the teaching process. This study focuses on teachers' interventions, as they diagnose and facilitate these multiple, dynamic situations. These four case studies assist us to better understand the diverse approaches that teachers take in these situations.

Jankvist and Misfeldt (2021) write about how "old" cognitive frameworks of mathematics can be used to better understand the use of Computer Algebra Systems (CAS) in Danish upper secondary school mathematics programs. They explore the use of CAS in mathematical concept formation, mathematical proofs, and classroom teaching. They argue that the "old" frameworks better address the use of the new technologies. They propose that we should learn more about the "classical constructs of our field" as we explore complex problems and challenges, particularly in the use of technology to teach mathematics.

Talin and Antoine (2021) investigated student attitudes towards science by surveying 1352 first year university students enrolled in science courses at the University of Lille in France. They found significant differences in attitudes towards science that was mostly correlated to the field chosen by the student. Their study provides the reader with some interesting insights into science attitudes of university students.

Aikenhead (2021) explores the cultural understanding of human sense-making of teachers of Grades 7 to 12 and their students. He suggests that a humanistic-oriented school mathematics program will engage the majority of Grades 7 to 12 students. Aikenhead uses humanistic mathematics lessons and modules to illustrate this new model. He also proposes that a Platonist mathematics program will play an important role for a minority of students preparing for entry into the advanced mathematics employment sector. He concludes by suggesting that some students may enroll in both programs. 
The articles in this issue provide an opportunity for the reader to explore topics that might be outside of their regular reading. We can expand our knowledge through our personal and professional exploration of related and new topics. The editors and staff of CJSMTE hope that this issue will provide you with that new knowledge.

\section{Declarations}

Competing Interests The author declares no competing interests.

\section{References}

Abboud, M., \& Rogalski, J. (2021). Open dynamic situations of classroom use of Digital Technologies: investigating teachers' interventions. Canadian Journal of Science, Mathematics and Technology Education, 21(2). https://doi. org/10.1007/s42330-021-00151-9

Aikenhead, G. S. (2021). Resolving conflicting subcultures within school mathematics: Towards a humanistic school mathematics. Canadian Journal of Science, Mathematics and Technology Education, 21(2). https://doi.org/10.1007/ s42330-021-00152-8

Braund, M. R. (2021). Critical STEM literacy and the COVID-19 Pandemic. Canadian Journal of Science, Mathematics and Technology Education, 21(2). https://doi.org/10.1007/s42330-021-00150-w

Bronkhorst, H., Roorda, G., Suhre, C., \& Goedhart, M. (2021). Student development in logical reasoning: Results of an intervention guiding students through different modes of visual and formal representation. Canadian Journal of Science, Mathematics and Technology Education, 21(2). https://doi.org/10.1007/s42330-021-00148-4

George, L. \& Voutsina, C. (2021). Variations in partitive quotient strategy use by children who have been taught the partwhole fraction sub-construct. Canadian Journal of Science, Mathematics and Technology Education, 21(2). https:// doi.org/10.1007/s42330-021-00147-5

Jankvist, U. T., \& Misfeldt, M. (2021). Old frameworks - new technologies. Canadian Journal of Science, Mathematics and Technology Education, 21(2). https://doi.org/10.1007/s42330-021-00164-4

Marchand, P., \& Munier, V. (2021). Un levier pour une meilleure appréhension de l'espace en classe de sciences à l'école. Canadian Journal of Science, Mathematics and Technology Education, 21(2). https://doi.org/10.1007/ s42330-021-00143-9

Nxumalo, F. \& Gitari, W. (2021). Responding to Anti-Black Racism in Science, Mathematics, Technology, and STEM Education. Canadian Journal of Science, Mathematics and Technology Education, 21(2). https://doi.org/10.1007/ s42330-021-00160-8

Ramírez Montes, G., Henriques, A., \& Carreira, S. (2021). Undergraduate students' learning of linear algebra through mathematical modeling routes. Canadian Journal of Science, Mathematics and Technology Education, 21(2). https:// doi.org/10.1007/s42330-021-00149-3

Talin, K., \& Antoine, A-F. P. (2021). La représentation de la science est-elle genrée? Étude auprès des étudiantes et étudiants inscrits en première année de filière scientifique à l'université de Lille. Canadian Journal of Science, Mathematics and Technology Education, 21(2). https://doi.org/10.1007/s42330-021-00156-4

Publisher's Note Springer Nature remains neutral with regard to jurisdictional claims in published maps and institutional affiliations. 